\title{
The Health and Well-Being of Transgender Australians: A National Community Survey
}

\author{
Ingrid Bretherton, MBBS, ${ }^{1,2}$ Emily Thrower, MD, Sav Zwickl, MSexol, ${ }^{1}$ Alex Wong, ${ }_{1}^{1}$ \\ Daria Chetcuti, ${ }^{1}$ Mathis Grossmann, PhD, ${ }^{1,2}$ Jeffrey D. Zajac, PhD, ${ }^{1,2}$ and Ada S. Cheung, PhD ${ }^{1,2}$
}

\section{Abstract}

Purpose: Transgender, including gender diverse and nonbinary (trans), people experience significant health disparities. We aimed to better understand the health status and needs of Australian trans people to guide resources and health and well-being programs.

Methods: This anonymous, cross-sectional online survey utilized nonprobability snowball sampling of Australian adults (18 years and over) who self-identified as trans between September 2017 and January 2018. This descriptive study assessed demographic data, community views on access to health care, health burden, access to health resources, and priorities for government funding in transgender health.

Results: Of 928 participants, 37\% reported female, 36\% reported male, and 27\% reported nonbinary gender identities. Despite $47 \%$ having tertiary qualifications, the unemployment rate was $19 \%$, with $33 \%$ reporting discrimination in employment due to being trans. Discrimination in accessing health care was reported by $26 \%$ and verbal abuse and physical assault were reported by $63 \%$ and $22 \%$, respectively. Lifetime diagnosis of depression was reported by $73 \%$ and anxiety by $67 \%$. Sixty-three percent reported previous self-harm and $43 \%$ had attempted suicide. Autism spectrum disorder and attention-deficit/hyperactivity disorder were reported by $15 \%$ and $11 \%$, respectively. The most preferred method of receiving health information was through online resources, with the most popular source being Reddit, an online peer discussion board. Better training for doctors in trans health issues was the top priority for government funding.

Conclusions: Barriers, including widespread discrimination and unemployment, contribute to health inequity and prevalent mental health conditions. Better training for health professionals in the provision of safe, genderaffirming and general health care for trans people is urgently required.

Keywords: barriers to care, gender-affirming endocrine care, gender-affirming surgical care, gender dysphoria, transgender

\section{Introduction}

$\mathbf{T}$ HE NUMBER OF TRANSGENDER, including gender diverse and nonbinary (trans), individuals seeking genderaffirming health care worldwide is rising, ${ }^{1}$ yet global studies have demonstrated that trans people face many barriers to accessing health care, including discrimination ${ }^{2}$ and the inability to find doctors willing to provide care, ${ }^{3}$ as well as high rates of depression and attempted suicide. ${ }^{1,4}$ Mental health distress is driven, in part, by barriers to accessing health care as well as by discrimination. ${ }^{1,5-8}$ In addition, cooccurring autism spectrum disorders (ASD) and attentiondeficit/hyperactivity disorder (ADHD) may also be more prevalent among trans individuals for unclear reasons, with difficulties with attention or social interaction potentially posing greater barriers by affecting the ability to understand health information or engage in clinical care. ${ }^{1,9}$

There are little data describing the health of the Australian adult trans population. Due to a lack of population data, it is unknown how many Australians identify as trans. A nonpeer-reviewed publication described very high levels of mental health conditions, particularly depression and anxiety syndromes, poor quality of life, and high rates of discrimination among Australian trans adults in 2013 (Ref. ${ }^{10}$ ). Similarly, high rates of mental health conditions were observed in trans adults attending specialized

\footnotetext{
${ }^{1}$ Department of Medicine (Austin Health), The University of Melbourne, Victoria, Australia.

${ }^{2}$ Department of Endocrinology, Austin Health, Heidelberg, Victoria, Australia.

(c) Ingrid Bretherton et al. 2020; Published by Mary Ann Liebert, Inc. This Open Access article is distributed under the terms of the Creative Commons License (http://creativecommons.org/licenses/by/4.0), which permits unrestricted use, distribution, and reproduction in any medium, provided the original work is properly cited.
} 
gender affirmation clinics in the state of Victoria; however, these findings may not be generalizable. ${ }^{1}$

Australia's universal health care system provides free or low-cost, government-subsidized general health services, including general or specialist consultations, pathology collection, and medications, including gender-affirming hormones. However, in regions with fewer specialized gender services, access to low-cost options may be limited.

Access to gender-affirming interventions in Australia typically follows one of two pathways; either a formal assessment and approval by a mental health professional as per the World Professional Association for Transgender Health Standards of Care ${ }^{11}$ or an alternative informed consent model of care where a decision to commence gender-affirming hormones is shared between a primary care general practitioner and a trans individual without mandating a formal mental health review. ${ }^{12}$ Due to a lack of publicly funded gender-affirming surgery, this is provided almost entirely in the private health sector, which carries significant out-of-pocket costs.

This community-based survey sought to better understand the health needs of Australian trans individuals to direct local health resources to best meet health care needs. We hypothesized that transgender individuals have significant barriers to accessing health care, including socioeconomic disadvantage, high burden of co-occurring mental health conditions, and discrimination. The aim of this descriptive study was to assess the sociodemographic characteristics and medical and mental health conditions affecting adult trans Australians; to obtain views on health burden, ability to access health care, and ability to access health resources; and to understand community views on funding priorities for trans health.

\section{Methods}

This anonymous community survey utilized a nonprobability snowball sampling approach to survey trans Australian adults aged 18 years and over using an online survey platform (SurveyMonkey, Inc., USA) between September 1, 2017, and January 31, 2018. The full survey is listed in Supplementary Appendix SA1. Participants were recruited through the Trans Health Research group Facebook page and the study also was promoted at the Australian and New Zealand Professional Association for Transgender Health Biennial Meeting in Sydney, Australia, in September 2017 and at the Midsumma LGBTIQ+ Festival in Melbourne, Australia, in January 2018. Written informed consent was not possible given the anonymous online design; however, the survey preamble outlined that completion of the survey implied consent. The survey link was available as a URL and did not require access to a specific social media account. The study was approved by the Austin Health Human Research and Ethics Committee (HREC/17/Austin/372).

Inclusion criteria were assessed through a positive response to three screening questions: (1) residency in Australia; (2) identification as trans or had previously identified as such; and (3) aged 18 years or over. The inclusion of those who had previously identified as trans was intended to include those who identified as their affirmed gender (male or female) rather than with the term transgender. Individuals were eligible to complete the survey on one oc- casion only and duplicate responses from the same internet protocol address were excluded. All included individuals had discordance between their assigned sex at birth and their gender identity. Other than the initial screening questions, all subsequent survey questions were optional.

\section{Demographic data}

Participants' birth years and postcodes were obtained. Postcodes were coded as per the Australian Standard Geographical Classification-Remoteness Area (RA) coding ${ }^{13}$ to one of five groups; RA1 (inner cities) to RA5 (very remote). Participants were asked to select their sex assigned at birth (male, female, or intersex) and their gender identity (see Table 1 for options). To enable meaningful statistical analyses, gender identities were then further categorized into three groups: trans man/trans male/trans masculine and male gender identities were coded as male identities; trans woman/trans female/trans feminine and female were coded as female identities; and gender nonbinary, gender queer, gender neutral, gender fluid, intersex, and agender were coded as nonbinary gender identities. Those who selected "other" also entered free text and were reclassified accordingly. Formal education, requirement for government financial assistance, and employment status were assessed (responses as outlined in Table 1). Participants were able to select more than one employment status. To reflect engagement with the workforce, if two options were selected, individuals were classified in the group that reflected the most workforce engagement. For example, if a person was a student and casually employed, they were classified as casually employed.

\section{Access to health care and health burden}

Current smoking and past 12-month illicit drug use were self-reported, and self-perception of overall health was evaluated (responses available outlined in Table 2). Participants were asked about their access to various types of health care providers, including availability of general practitioners and their confidence in discussing health issues of concern with their treating doctor. As discrimination has been identified as a barrier to health care in previous surveys,${ }^{14}$ participants were asked if they had perceived discrimination in employment, housing, accessing health care, and government services and/or whether they had experienced physical assault, verbal abuse, and domestic violence because of their gender identity. trans individuals were asked whether they had experienced any difficulty accessing hormonal treatment (such as the inability to find a doctor who is willing to prescribe, financial costs of prescriptions, financial costs of doctor's appointments, or other [specify]). Participants were also asked if they had taken any hormonal treatments without a prescription.

To assess the community's value of mental health assessments before commencing gender-affirming hormonal treatment, participants were asked "Do you feel that a mental health assessment for trans and gender diverse individuals should be performed prior to accessing hormonal treatment?" Assessment of access to and desire for genderaffirming hormonal and surgical treatments and previous medical and mental health conditions relied on selfreporting, and no specific diagnostic tools were used. History of self-harm or attempted suicide was also ascertained. 
TABle 1. Sociodemographic Parameters OF THE PARTICIPANTS

\begin{tabular}{|c|c|c|}
\hline Parameter & $\begin{array}{c}\text { Number of } \\
\text { responses } \\
\text { received }\end{array}$ & $\begin{array}{l}\text { Frequency, } \\
\text { n (\%) }\end{array}$ \\
\hline State of residence & 911 & \\
\hline Victoria & & $282(31)$ \\
\hline New South Wales & & $195(21)$ \\
\hline Queensland & & $143(16)$ \\
\hline Western Australia & & $126(14)$ \\
\hline South Australia & & $92(10)$ \\
\hline Tasmania & & $37(4)$ \\
\hline Australian Capital Territory & & $34(4)$ \\
\hline Northern Territory & & $2(<1)$ \\
\hline Age group (years) & 928 & \\
\hline $18-24$ & & $289(31)$ \\
\hline $25-29$ & & $216(23)$ \\
\hline $30-39$ & & $193(21)$ \\
\hline $40-49$ & & $125(13)$ \\
\hline $50-59$ & & $71(8)$ \\
\hline $60-69$ & & $30(3)$ \\
\hline 70-79 & & $4(<1)$ \\
\hline Sex assigned at birth & 928 & \\
\hline Female & & $520(56)$ \\
\hline Male & & $403(43)$ \\
\hline Intersex & & $5(1)$ \\
\hline Gender identity & 928 & \\
\hline Male & & $91(10)$ \\
\hline Female & & $140(15)$ \\
\hline $\begin{array}{l}\text { Trans man/trans male/trans } \\
\text { masculine }\end{array}$ & & $239(26)$ \\
\hline $\begin{array}{l}\text { Trans woman/trans } \\
\text { female/trans feminine }\end{array}$ & & $202(22)$ \\
\hline Gender nonbinary & & $133(14)$ \\
\hline Gender queer & & $41(4)$ \\
\hline Gender neutral & & $11(1)$ \\
\hline Gender fluid & & $19(2)$ \\
\hline Intersex & & $2(<1)$ \\
\hline Agender & & $20(2)$ \\
\hline Other & & $30(3)$ \\
\hline Education level & 928 & \\
\hline Never attended school & & $1(<1)$ \\
\hline Primary school & & 0 \\
\hline Some high school & & $98(11)$ \\
\hline Completed high school & & $222(24)$ \\
\hline $\begin{array}{l}\text { Trade/technical certificate } \\
\text { or apprenticeship }\end{array}$ & & $170(18)$ \\
\hline $\begin{array}{l}\text { University or tertiary } \\
\text { qualifications }\end{array}$ & & $437(47)$ \\
\hline Employment status & 928 & \\
\hline Employed on a full-time basis & & $274(30)$ \\
\hline $\begin{array}{l}\text { Employed on a part-time } \\
\text { or casual basis }\end{array}$ & & $224(24)$ \\
\hline Home duties full-time & & $13(1)$ \\
\hline Student & & $176(19)$ \\
\hline Retired & & $20(2)$ \\
\hline Unemployed & & $177(19)$ \\
\hline Other (free text) & & $44(5)$ \\
\hline
\end{tabular}

\section{Access to health resources and priorities for government funding}

Preferred methods (i.e., social media, online resources, videos, forums, and print) of receiving health information were assessed, including involvement in support groups and websites used to locate information on trans health. Desire for local, Australian-based, trans health resources was also determined. Participants selected the areas of priority to which they thought resources should be directed (education about gender diversity, gender clinics, support groups, trans advocacy groups, counseling, better training for doctors in trans issues, transgender medical research, psychology/ psychiatry services, or other [free text]). Qualitative analysis results of several open-ended questions regarding health issues of concern have been reported separately. ${ }^{15}$

\section{Statistical analysis}

Statistical analysis was performed using SPSS Statistics, version 23 (IBM Corporation, Armonk, NY). Descriptive frequencies are reported and medians (interquartile range) are reported for non-normally distributed data.

\section{Results}

The survey social media post was shared by 275 individuals and transgender support groups on the social media site Facebook. A total of 964 responses to the survey were obtained. After excluding duplicates from the same IP address, blank surveys, or those that did not meet the inclusion criteria (based on the previously described screening questions), 928 eligible responses remained.

\section{Sociodemographic data}

As shown in Table 1, responses were received from every Australian state and territory. The greatest number of participants $(n=282,31 \%)$ resided in Victoria. Eighty-three percent $(n=752)$ of those that responded resided in inner city areas (RA1). Median age was 28 years (interquartile range 23-39). Thirty-seven percent $(n=342)$ reported female identities, 36\% $(n=330)$ reported male identities, and $27 \%$ $(n=256)$ reported nonbinary gender identities. Participants had high levels of education, with $47 \%(n=437)$ holding a university qualification. The unemployment rate was $19 \%$ $(n=177)$. The majority $(n=376,57 \%)$ reported receiving some form of government financial assistance.

\section{Access to health care and health burden}

Table 2 outlines responses describing access to health care and health burden. Current smoking in $15 \%(n=141)$ of participants is comparable with national data indicating that $11.6 \%$ of Australian adults reported smoking cigarettes daily. ${ }^{16}$ Illicit drug use was high, with $33 \%(n=305)$ of respondents reporting use of illicit drugs in the past 12 months and is approximately double the general Australian population rate of illicit drug use of $16.4 \%$ in the preceding 12 months in 2019 (reported in people aged 14 years and over). ${ }^{17}$ Nearly $80 \%(n=711)$ described at least good health and $80 \%(n=732)$ had a regular family doctor or general practitioner. When asked if individuals had ever experienced any difficulty accessing hormonal treatment, $41 \%(n=372)$ selected "none." A third $(n=284)$ reported that the pathway to accessing hormones was too difficult. Discrimination because of gender identity was widespread, with $33 \%$ $(n=304)$ reporting discrimination related to employment and $26 \%(n=244)$ related to accessing health care. Verbal 
Table 2. Access to Health Care AND Health Burden

\begin{tabular}{|c|c|c|}
\hline Parameter & $\begin{array}{l}\text { Number of } \\
\text { responses } \\
\text { received }\end{array}$ & $\begin{array}{l}\text { Frequency, } \\
\mathrm{n}(\%)\end{array}$ \\
\hline Self-perception of overall health & 907 & \\
\hline Excellent & & $86(9)$ \\
\hline Very good & & $224(25)$ \\
\hline Good & & $401(44)$ \\
\hline Poor & & $171(19)$ \\
\hline Very poor & & $25(3)$ \\
\hline Health care providers utilized ${ }^{\mathrm{a}}$ & 928 & \\
\hline GP & & $779(84)$ \\
\hline Psychologist & & $631(68)$ \\
\hline Psychiatrist & & $508(55)$ \\
\hline Endocrinologist & & $413(45)$ \\
\hline Surgeon & & $298(32)$ \\
\hline Nurse & & $235(25)$ \\
\hline Speech pathologist & & $117(13)$ \\
\hline Gender clinic within a hospital & & $103(11)$ \\
\hline Gynecologist & & $87(9)$ \\
\hline None & & $89(10)$ \\
\hline Other (free text) & & $32(3)$ \\
\hline Discrimination $^{\mathrm{a}}$ & 927 & \\
\hline Discrimination in employment & & $304(33)$ \\
\hline $\begin{array}{l}\text { Discrimination in accessing } \\
\text { health care }\end{array}$ & & $244(26)$ \\
\hline $\begin{array}{l}\text { Discrimination in government } \\
\text { services }\end{array}$ & & $149(16)$ \\
\hline Discrimination in housing & & $95(10)$ \\
\hline Verbal abuse & & $584(63)$ \\
\hline Physical assault & & $200(22)$ \\
\hline Domestic violence & & $133(14)$ \\
\hline $\begin{array}{l}\text { Difficulty accessing hormonal } \\
\text { treatment }^{\mathrm{a}}\end{array}$ & 905 & \\
\hline None & & $372(41)$ \\
\hline $\begin{array}{l}\text { Unable to find a doctor to } \\
\text { prescribe }\end{array}$ & & $148(16)$ \\
\hline Financial costs of prescriptions & & $124(14)$ \\
\hline $\begin{array}{l}\text { Financial costs of doctor's } \\
\text { appointments }\end{array}$ & & $156(17)$ \\
\hline $\begin{array}{l}\text { Pathway to accessing hormones } \\
\text { was too difficult }\end{array}$ & & $284(31)$ \\
\hline Other (specify) & & $100(11)$ \\
\hline $\begin{array}{l}\text { Views on informed consent-- } \\
\text { Should trans people undertake a } \\
\text { formal mental health } \\
\text { practitioner assessment? }\end{array}$ & 913 & \\
\hline Yes, in all cases & & $285(31)$ \\
\hline $\begin{array}{l}\text { Yes, but only in some } \\
\text { circumstances }\end{array}$ & & $392(43)$ \\
\hline No & & $187(20)$ \\
\hline Unsure & & $48(5)$ \\
\hline $\begin{array}{l}\text { Masculinizing hormone treatments } \\
\text { in birth-assigned females }{ }^{\mathrm{a}}\end{array}$ & 509 & \\
\hline None & & $191(38)$ \\
\hline Testosterone injections & & $267(53)$ \\
\hline $\begin{array}{l}\text { Testosterone creams, gels, or } \\
\text { patches }\end{array}$ & & $45(9)$ \\
\hline Testosterone implants & & $2(<1)$ \\
\hline GnRH analogs & & $2(<1)$ \\
\hline Progestins & & $4(<1)$ \\
\hline
\end{tabular}

(continued)
TABLE 2. (CONTINUED)

\begin{tabular}{|c|c|c|}
\hline Parameter & $\begin{array}{l}\text { Number of } \\
\text { responses } \\
\text { received }\end{array}$ & $\begin{array}{l}\text { Frequency, } \\
\mathrm{n}(\%)\end{array}$ \\
\hline Other & & $7(1)$ \\
\hline $\begin{array}{l}\text { Feminizing hormone treatments in } \\
\text { birth-assigned males }\end{array}$ & 402 & \\
\hline None & & $75(19)$ \\
\hline Estradiol oral tablets & & $205(51)$ \\
\hline Estradiol transdermal patches & & $56(14)$ \\
\hline Estradiol gels & & $33(8)$ \\
\hline Estradiol implants & & $52(13)$ \\
\hline $\begin{array}{l}\text { Combined oral contraceptive } \\
\text { pill }\end{array}$ & & $14(3)$ \\
\hline Spironolactone & & $130(32)$ \\
\hline Cyproterone acetate & & $106(26)$ \\
\hline Bicalutamide & & $1(<1)$ \\
\hline GnRH analogs & & $2(<1)$ \\
\hline $\begin{array}{l}\text { Progestins or micronized } \\
\text { progesterone }\end{array}$ & & $63(16)$ \\
\hline $\begin{array}{l}\text { Other (i.e., finasteride or } \\
\text { estradiol injections) }\end{array}$ & & $11(3)$ \\
\hline Overseas surgery & 914 & \\
\hline Yes & & $72(8)$ \\
\hline No & & $841(92)$ \\
\hline Unsure/prefer not to say & & $1(<1)$ \\
\hline Medical conditions & 914 & \\
\hline Depression & & $663(73)$ \\
\hline Anxiety & & $613(67)$ \\
\hline Fractures (broken bone) & & $191(21)$ \\
\hline $\begin{array}{l}\text { Autism spectrum or Asperger's } \\
\text { syndrome }\end{array}$ & & $137(15)$ \\
\hline ADHD & & $96(11)$ \\
\hline Bipolar disorder & & $75(8)$ \\
\hline Diabetes mellitus & & $25(3)$ \\
\hline Cancer & & $19(2)$ \\
\hline $\begin{array}{l}\text { Blood clots (pulmonary } \\
\text { embolus or deep vein } \\
\text { thrombosis) }\end{array}$ & & $16(2)$ \\
\hline Liver disease & & $13(1)$ \\
\hline Stroke & & $11(1)$ \\
\hline HIV/AIDS & & $5(<1)$ \\
\hline Ischemic heart disease & & $4(<1)$ \\
\hline Emphysema & & $3(<1)$ \\
\hline Kidney or renal disease & & $3(<1)$ \\
\hline $\begin{array}{l}\text { None of the above options } \\
\text { selected }^{\mathrm{b}}\end{array}$ & & $136(15)$ \\
\hline
\end{tabular}

${ }^{a}$ Multiple responses were allowed for this question, so total responses do not sum to $100 \%$.

${ }^{\mathrm{b}}$ None was not an option in the survey but was presumed if no medical conditions were selected but answers were completed to the remaining questions in Section 2: Your Health of the survey.

ADHD, attention-deficit/hyperactivity disorder; $\mathrm{GnRH}$, gonadotropinreleasing hormone; GP, general practitioner; trans, transgender, including gender diverse and nonbinary.

abuse because of their trans status was reported by $63 \%$ of respondents and physical assault because of their trans status was reported by $22 \%$.

There were mixed responses to the need for a formal mental health assessment prior to commencement of hormonal therapy and it is acknowledged that wording of this question may have contributed to ambiguity (Table 2). There was a very high prevalence of self-reported depression and anxiety 
FIG. 1. Self-reported diagnoses in trans individuals versus the Australian population (age-matched). ${ }^{18-20}$ ADHD, attention-deficit/hyperactivity disorder; trans, transgender, including gender diverse and nonbinary.

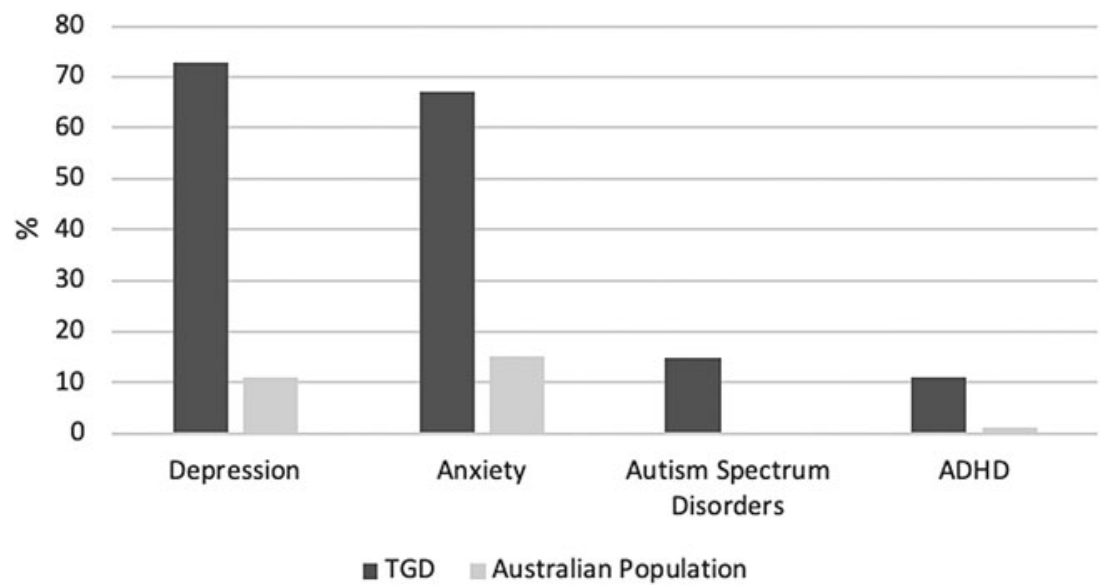

as well as ASD and ADHD (Fig. 1). ${ }^{18-20}$ Intentional selfharm was reported by $63 \%(n=577)$ of participants and $43 \%(n=394)$ reported having previously attempted suicide.

Gender-affirming surgical interventions are summarized in Table 3. Genital reconstruction surgery was the most common procedure undertaken by those assigned male at birth $(n=71,18 \%)$; however, a further $64 \%(n=243)$ desired this surgery in the future. The most frequent procedure undertaken by those assigned female at birth was bilateral mastectomy or chest reconstruction $(n=159$, $31 \%)$. Similarly, a further $58 \%(n=297)$ desired this procedure in the future.

\section{Access to health resources and priorities for government funding}

The most preferred method of receiving health information was through online resources $(n=400,50 \%)$ (Table 4$)$. Forty-three percent $(n=369)$ of participants used existing online sources for health information. The most popular source reported in this study was Reddit, an online discussion board with user-generated content, followed by Facebook, Susan's Place, FtM Australia, Wikipedia, YouTube, and Tumblr. The majority $(95 \%, n=814)$ supported the development of a comprehensive online website with local, Australian-based, trans health resources, and $89 \%$ of the participants $(n=768)$ used social media daily. Better training for doctors in trans issues was the most frequently selected priority for government funding $(32 \%, n=267)$; complete responses are listed in Table 4.

\section{Discussion}

This large community-based survey involving 928 participants described persistent, concerning health statistics among trans Australian adults: high rates of self-reported mental health morbidities, such as anxiety and depression, as well as high rates of self-reported self-harm $(63 \%)$ and attempted suicide $(43 \%)$. There were widespread experiences of discrimination, especially in health care settings (26\%). Moreover, a majority of the participants had experienced verbal abuse (63\%), with fewer reporting physical assault (22\%) because of their trans status. There were barriers to employment (19\% unemployed) despite high levels of tertiary education. Additional barriers to accessing health care existed, such as difficult ambiguous pathways for accessing gender-affirming hormonal therapy; difficulty finding doctors to prescribe treatment; and the potentially high, out-of-pocket financial costs of surgical care. Although the use of gender-affirming hormone therapy was common, significant difficulties existed in accessing gender-affirming surgery. Even though most of the participants accessed health information from peer-generated online websites, there was support for development of reliable, local health resources. Better training for doctors in trans health issues was highlighted as the top priority for government funding by $32 \%$ of participants.

\section{Sociodemographic data}

We observed a breadth of gender identities in the trans community across Australia with approximately equal

Table 3. Access to and Desire for Gender-Affirming Surgery

\begin{tabular}{|c|c|c|c|c|}
\hline & $\begin{array}{l}\text { Total number } \\
\text { of responses }\end{array}$ & $\begin{array}{l}\text { Have had, } \\
\mathrm{n}(\%)\end{array}$ & $\begin{array}{c}\text { Want someday, } \\
\mathrm{n}(\%)\end{array}$ & $\begin{array}{c}\text { Don't want, } \\
\text { n }(\%)\end{array}$ \\
\hline \multicolumn{5}{|c|}{ Surgical procedures in birth-assigned males $(n=403)$} \\
\hline Breast augmentation & 362 & $32(9)$ & $196(54)$ & $134(37)$ \\
\hline Genital reconstruction surgery & 384 & $71(18)$ & $243(64)$ & $70(18)$ \\
\hline Facial feminization surgery & 372 & $23(6)$ & $235(63)$ & $114(31)$ \\
\hline Voice surgery & 348 & $6(2)$ & $149(43)$ & $193(55)$ \\
\hline \multicolumn{5}{|c|}{ Surgical procedures in birth-assigned females $(n=520)$} \\
\hline Chest surgery/mastectomy & 511 & $159(31)$ & $297(58)$ & $55(11)$ \\
\hline Genital reconstruction surgery & 481 & $10(2)$ & $213(44)$ & $258(54)$ \\
\hline Voice surgery & 405 & $1(<1)$ & $15(4)$ & 389 (96) \\
\hline
\end{tabular}

Percentages are rounded to whole numbers. 
Table 4. Access to Health Resources AND PRIORITIES FOR GOVERNMENT FUNDING

\begin{tabular}{|c|c|c|}
\hline Parameter & $\begin{array}{l}\text { Number of } \\
\text { responses } \\
\text { received }\end{array}$ & $\begin{array}{l}\text { Frequency, } \\
\mathrm{n}(\%)\end{array}$ \\
\hline $\begin{array}{l}\text { Most preferred method of } \\
\text { receiving health information }\end{array}$ & 799 & \\
\hline $\begin{array}{l}\text { Online (websites and e-mail, } \\
\text { etc.) }\end{array}$ & & $400(50)$ \\
\hline Social media (e.g., Facebook) & & $150(19)$ \\
\hline Videos or podcasts & & $57(7)$ \\
\hline Telephone contact & & $43(5)$ \\
\hline $\begin{array}{l}\text { Hardcopy print materials (e.g., } \\
\text { brochures) }\end{array}$ & & $41(5)$ \\
\hline $\begin{array}{l}\text { Small local community } \\
\text { talks/seminars }\end{array}$ & & $39(5)$ \\
\hline Apps (on mobile devices) & & $35(4)$ \\
\hline $\begin{array}{l}\text { Online group forums (e.g., } \\
\text { webinars) }\end{array}$ & & $24(3)$ \\
\hline $\begin{array}{l}\text { Larger group gatherings (e.g., } \\
\text { conferences) }\end{array}$ & & $10(1)$ \\
\hline Social media use & 859 & \\
\hline Daily & & $768(89)$ \\
\hline Couple of times a week & & $55(6)$ \\
\hline Occasionally (e.g., once a week) & & $19(2)$ \\
\hline Rarely (e.g., once a fortnight) & & $10(1)$ \\
\hline Not at all & & $7(<1)$ \\
\hline $\begin{array}{l}\text { Top priority for government } \\
\text { funding }\end{array}$ & 824 & \\
\hline $\begin{array}{l}\text { Better training for doctors in } \\
\text { trans issues }\end{array}$ & & $267(32)$ \\
\hline Gender clinics & & $205(25)$ \\
\hline $\begin{array}{l}\text { Education about gender } \\
\text { diversity (i.e., community or } \\
\text { schools) }\end{array}$ & & $197(24)$ \\
\hline $\begin{array}{l}\text { Trans or gender-related medical } \\
\text { research }\end{array}$ & & $83(10)$ \\
\hline $\begin{array}{l}\text { Psychology or psychiatry } \\
\text { services }\end{array}$ & & $32(4)$ \\
\hline Support groups & & $18(2)$ \\
\hline Trans advocacy groups & & $14(2)$ \\
\hline Counseling & & $8(1)$ \\
\hline Other (free text) & & 0 \\
\hline
\end{tabular}

thirds of the participants having female, male, and nonbinary identities. This contrasts with historical reports that the prevalence of trans female individuals outnumbered trans male individuals. ${ }^{21}$ The high proportion of people with nonbinary gender identities is consistent with rates observed in our primary care clinics in Australia ${ }^{1}$ and may reflect increasing societal views that challenge binary gender stereotypes.

The unemployment rate of $19 \%$ was three times that of the Australian general population rate of $5.5 \%$ in May 2018 and well above the youth unemployment rate $(12.2 \%){ }^{22}$ Notably, $33 \%$ of respondents perceived discrimination in employment. Unemployment may also occur due to difficulty with name and identity documents, discrimination in basic housing and health care, ${ }^{5}$ and the impact of mental health conditions such as depression and anxiety on an individual's ability to seek or maintain employment. Conversely, levels of depression and anxiety may be higher due to unemployment. ${ }^{23}$

\section{Access to health care and health burden}

Similar to prior reports, ${ }^{5}$ discrimination in all aspects of life was frequently reported by trans Australians, which is not only harmful but also perpetuates inequity. Most concerning is that safe access to health care, which should be accessible to all, is not a reality for trans Australians and this is supported by the participants' selected top priority for government funding being better training for doctors in trans health issues. Access to surgery is a major challenge in Australia, with (anecdotally) few surgeons experienced in providing gender-affirming surgery. Moreover, surgery is predominantly provided in the private health system, which is associated with prohibitive financial costs. There is a need for education and training to target the number of surgeons providing gender-affirming surgery.

Self-reported depression and anxiety were highly prevalent in $\sim 70 \%$ of individuals, as were self-reported diagnoses of ASD and ADHD (Fig. 1). These are consistent with data from individuals attending specialized gender clinics ${ }^{1}$ as well as from international reports. ${ }^{24}$ Notably, a diagnosis of ADHD in childhood is associated with a higher risk of having at least one mental health condition and a higher risk of death by suicide. ${ }^{25}$ As positive screening tools for ASD may reflect elevated social anxiety experienced by trans people, data describing the coexistence of ASD are conflicting and further research is needed. ${ }^{9}$

The most concerning data are the self-reported self-harm and attempted suicide rates, a reflection of the severe distress and despair that many trans individuals have faced. These suicidality rates are much higher than the lifetime prevalence of suicide attempts in Australian adults (3.3\%). ${ }^{26}$ Our Australian data mirror findings in the U.S. National Transgender Discrimination Survey of 6450 trans Americans, which first highlighted widespread discrimination in many aspects of life, including double the rate of unemployment; 19\% being refused medical care due to their trans status; and $41 \%$ of suicide attempts (compared with $1.6 \%$ of the general population). ${ }^{27}$ Lack of acceptance in the community and, at times, among health professionals leaves few resources for trans individuals to access help and support. This is a significant public health concern and there is an urgent need for a coordinated and combined suicide prevention response.

\section{Health resources and priorities for government funding}

The top priority for government funding was better training in trans health issues for doctors. Although greater awareness of and more coordinated training in trans health need to occur, in response to findings from this study, an evidence-based local position statement was published regarding the hormonal management of trans adults to provide a pointof-care resource for doctors caring for trans individuals. ${ }^{12}$ In response to the community desire for Australian-based trans health information, we contributed to the development of trans community-led online health resources (Trans Health Research and TransHub). ${ }^{28,29}$

\section{Limitations}

There are multiple limitations to this study. The onlinebased recruitment may explain why a greater proportion of responders were younger individuals and may not accurately reflect the views of the older trans community. There may be 
self-selection bias and not all areas of Australia were equally represented as recruitment was not targeted. There was a predominance of respondents from southeastern states, which may be related to physical promotion of the study at one event in Victoria and one in New South Wales. However, distribution of respondents was similar to a previous 2013 Western Australian-based survey. ${ }^{10}$ Ethnicity data were not collected, so we were unable to ascertain if this was a factor associated with additional barriers when accessing health care. Medical conditions were self-reported, and we were not able to utilize any diagnostic measures to confirm diagnoses. Furthermore, we did not gauge temporal trends in diagnoses and did not distinguish current from past medical conditions, which may be particularly relevant in the interpretation of the prevalence of ADHD. Participants were asked whether a mental health assessment for trans and gender diverse individuals should be performed prior to accessing hormonal treatment. There was likely a response bias in favor of the mental health assessment model as we did not make it clear that we were referring to a formal mental health assessment by a psychologist or psychiatrist rather than by the primary care physician in the wording of this question.

However, this survey provided a platform for participants to express their views anonymously, which potentially facilitated the expression of more honest responses than a face-to-face interview or government statistics form. The fact that many of our findings, although self-reported (such as rates of selfharm), replicate those from prior similar studies conducted with other transgender populations supports both the validity and the generalizability of our findings. Despite the limitations, this is one of the largest published studies of adult trans individuals in the Australian population and provides valuable insight on the status of health and health needs of a traditionally marginalized community that is underrepresented in research.

\section{Conclusions}

This large community survey highlights a myriad of challenges faced by trans adult Australians, including discrimination, abuse, unemployment, and inability to find doctors to access general health care and gender-affirming care. Reducing the high attempted suicide rate and burden of mental health conditions needs to be prioritized. The participants in this study identified the training of doctors in trans health as a priority. This should be one of the first steps to ensure that basic health needs are met. Urgent action is required from a policy perspective to address the concerning health disparities described herein and to ensure that all trans people are safe and empowered to live a life without barriers.

\section{Acknowledgments}

The authors would like to acknowledge members of the transgender community who reviewed and contributed to the survey design.

\section{Author Disclosure Statement}

A.S.C. has received speaker's honoraria from AstraZeneca and Merck Sharp and Dohme Corp. M.G. has received research funding from Bayer, Weight Watchers, and Eli Lilly and speaker's honoraria from Besins Healthcare and Novartis. All other authors have no conflicts of interest to declare.

\section{Funding Information}

I.B. receives salary support from an Australian Government Research Training Program Scholarship and a Rowden White Scholarship (application ref: 184409), The University of Melbourne. A.S.C. receives salary support from an Australian Government National Health and Medical Research Council Early Career Fellowship (No. 1143333) and research support from the Austin Medical Research Foundation.

\section{Supplementary Material}

Supplementary Appendix SA1

\section{References}

1. Cheung AS, Ooi O, Leemaqz S, et al.: Sociodemographic and clinical characteristics of transgender adults in Australia. Transgend Health 2018;3:229-238.

2. White Hughto JM, Rose AJ, Pachankis JE, Reisner SL: Barriers to gender transition-related healthcare: Identifying underserved transgender adults in Massachusetts. Transgend Health 2017;2:107-118.

3. Sanchez NF, Sanchez JP, Danoff A: Health care utilization, barriers to care, and hormone usage among male-to-female transgender persons in New York City. Am J Public Health 2009;99:713-719.

4. Adams NJ, Vincent B: Suicidal thoughts and behaviors among transgender adults in relation to education, ethnicity, and income: A systematic review. Transgend Health 2019; 4:226-246.

5. Bradford J, Reisner SL, Honnold JA, Xavier J: Experiences of transgender-related discrimination and implications for health: Results from the Virginia Transgender Health Initiative Study. Am J Public Health 2013;103:1820-1829.

6. Christian R, Mellies AA, Bui AG, et al.: Measuring the health of an invisible population: Lessons from the Colorado Transgender Health Survey. J Gen Intern Med 2018; 33:1654-1660.

7. Lykens JE, LeBlanc AJ, Bockting WO: Healthcare experiences among young adults who identify as genderqueer or nonbinary. LGBT Health 2018;5:191-196.

8. Giblon R, Bauer GR: Health care availability, quality, and unmet need: A comparison of transgender and cisgender residents of Ontario, Canada. BMC Health Serv Res 2017;17:283.

9. Thrower E, Bretherton I, Pang KC, et al.: Prevalence of autism spectrum disorder and attention-deficit hyperactivity disorder amongst individuals with gender dysphoria: A systematic review. J Autism Dev Disord 2020;50:695-706.

10. Hyde Z, Doherty M, Tilley PJM, et al.: The First Australian National Trans Mental Health Study: Summary of Results. 2014. School of Public Health, Curtin University, Perth, Australia.

11. Coleman E, Bockting W, Botzer M, et al.: Standards of care for the health of transsexual, transgender, and gendernonconforming people, Version 7. Int J Transgend 2012; 13:165-232.

12. Cheung AS, Wynne K, Erasmus J, et al.: Position statement on the hormonal management of adult transgender and gender diverse individuals. Med J Aust 2019;211:127-133.

13. Australian Government Australian Institute of Health and Welfare 2016. The Australian Statistical Geography Standard (ASGS) Remoteness Structure. Canberra AIHW. Available at https://www.abs.gov.au/websitedbs/d3310114 .nsf/home/remoteness+structure Accessed October 1, 2020. 
14. Jaffee KD, Shires DA, Stroumsa D: Discrimination and delayed health care among transgender women and men: Implications for improving medical education and health care delivery. Med Care 2016;54:1010-1016.

15. Zwickl S, Wong A, Bretherton I, et al.: Health needs of trans and gender diverse adults in Australia: A qualitative analysis of a national community survey. Int J Environ Res Public Health 2019;16:5088.

16. Greenhalgh EM, Bayly M, Scollo MM. 1.3 Prevalence of smoking-adults. In: Tobacco in Australia: Facts and Issues. Edited by Greenhalgh EM, Scollo MM, Winstanley MH. Melbourne: Cancer Council Victoria, 2020. Available at www.tobaccoinaustralia.org.au/chapter-1-prevalence/1-3prevalence-of-smoking-adults Accessed October 1, 2020.

17. Australian Institute of Health and Welfare 2020. National Drug Strategy Household Survey 2019. Drug Statistics series no. 32. PHE 270. Canberra AIHW. Available at https://www.aihw.gov.au/getmedia/3564474e-f7ad-461cb918-7f8de03d1294/aihw-phe-270-NDSHS-2019.pdf Accessed October 1, 2020.

18. Australian Bureau of Statistics. National Health Survey: First Results, 2017-18. 2018. Available at https://www.abs .gov.au/statistics/health/health-conditions-and-risks/nationalhealth-survey-first-results/2017-18/4364055001do003 20172018.xls Accessed July 30, 2020.

19. Ebejer JL, Medland SE, van der Werf J, et al.: Attention deficit hyperactivity disorder in Australian adults: Prevalence, persistence, conduct problems and disadvantage. PLoS One 2012;7:e47404.

20. Australian Bureau of Statistics. Survey of Disability, Ageing and Carers (SDAC) 2018. Available at https://www .abs.gov.au/statistics/health/disability/disability-ageing-andcarers-australia-summary-findings/latest-release Accessed October 29, 2020.

21. Bouman WP, Claes L, Marshall E, et al.: Sociodemographic variables, clinical features, and the role of preassessment cross-sex hormones in older trans people. J Sex Med 2016; 13:711-719.
22. Australian Bureau of Statistics. Labour Force, Australia, May 2018. Available at https://www.ausstats.abs.gov.au/ ausstats/meisubs.nsf/0/4A6AF94624BEB836CA2582AB0 016949D/\$File/62020_may_2018.pdf Accessed July 30, 2020.

23. Crowe L, Butterworth P: The role of financial hardship, mastery and social support in the association between employment status and depression: Results from an Australian longitudinal cohort study. BMJ Open 2016;6:e009834.

24. Reisner SL, Biello KB, White Hughto JM, et al.: Psychiatric diagnoses and comorbidities in a diverse, multicity cohort of young transgender women: Baseline findings from Project LifeSkills. JAMA Pediatr 2016;170:481-486.

25. Barbaresi WJ, Colligan RC, Weaver AL, et al.: Mortality, ADHD, and psychosocial adversity in adults with childhood ADHD: A prospective study. Pediatrics 2013;131:637-644.

26. Slade T, Johnston A, Teesson M, et al.: The mental health of Australians 2. Report on the 2007 National Survey of Mental Health and Wellbeing. 2009. Canberra, Australia: The Department of Health, Australian Government.

27. Grant JM, Mottet LA, Tanis J, et al.: Injustice at Every Turn: a Report of the National Transgender Discrimination Survey. 2011. Washington, DC: National Center for Transgender Equality and National Gay and Lesbian Task Force.

28. Trans Health Research. 2020. Available at https://www .transresearch.org.au Accessed July 30, 2020.

29. TransHub. 2020. Available at https://www.transhub.org.au Accessed July 30, 2020.

Address correspondence to: Ada S. Cheung, PhD Department of Endocrinology Austin Health 145 Studley Road Heidelberg, Victoria 3084 Australia

E-mail: adac@unimelb.edu.au 